\title{
Extracellular Ubiquitin is the Causal Link between Stored Blood Transfusion Therapy and Tumor Progression in a Melanoma Mouse Model
}

\author{
Jingjun Zhang ${ }^{*}$, Shuying Chen ${ }^{2 *}$, Yuzhong Yan $^{1 *}$, Xinfang Zhu1 ${ }^{1}$, Qi Qi1, Yang Zhang ${ }^{3}$, Qi Zhang1 ${ }^{\bowtie}$, Rong \\ $\mathrm{Xia}^{1 凶}$ \\ 1. Department of Transfusion, Huashan Hospital, Fudan University, Shanghai, China. \\ 2. Department of Laboratory Medicine, Huashan Hospital, Fudan University, Shanghai, China. \\ 3. Department of Oncology, People's Hospital of Pudong District, Shanghai, China. \\ *These authors contributed equally to this work. \\ $\triangle$ Corresponding authors: Rong Xia, Department of transfusion, Huashan Hospital, Fudan University, 12 Wulumuqi Middle Road, Jingan District, Shanghai \\ 200040, China. Phone: 8621-5288-8331; E-mail: xiarongcn@126.com; and Qi Zhang, Department of transfusion, Huashan Hospital, Fudan University, 12 \\ Wulumuqi middle Road, Jingan District, Shanghai 200040, China. Phone: 8621-6689-5067; E-mail: zhangqfdhs@163.com \\ ( ) Ivyspring International Publisher. This is an open access article distributed under the terms of the Creative Commons Attribution (CC BY-NC) license \\ (https://creativecommons.org/licenses/by-nc/4.0/). See http://ivyspring.com/terms for full terms and conditions.
}

Received: 2018.11.08; Accepted: 2019.04.28; Published: 2019.06.02

\begin{abstract}
Background: The transfusion of blood that has been stored for some time was found to be associated with transfusion-related immune modulation (TRIM) responses in cancer patients, which could result in poor clinical outcomes, such as tumor recurrence, metastasis and reduced survival rate. Given the prior observation of the positive correlation between ubiquitin content in whole blood and storage duration by the investigators of the present study, it was hypothesized that this could be the causal link behind the association between the transfusion of stored blood and poor cancer prognosis.

Methods: In the present study, a melanoma mouse model was used to study the potential clinical impact of ubiquitin present in stored blood on cancer prognosis through a variety of cell biology methods, such as flow cytometry and immunohistochemistry.

Results: Both extracellular ubiquitin and the infusion of stored mice blood that comprised of ubiquitin reduced the apoptotic rate of melanoma cells, promoted lung tumor metastasis and tumor progression, and reduced the long-term survival rate of melanoma mice. In addition, the upregulation of tumor markers and tumorigenic $\mathrm{TH} 2$ cytokine generation, as well as reduced immune cell numbers, were observed in the presence of ubiquitin.

Conclusions: The present findings provide novel insights into the role of ubiquitin in immune regulation in a melanoma mouse model, and suggest ubiquitin as the causal link between allogeneic blood transfusion therapy and poor cancer prognosis.
\end{abstract}

Key words: allogeneic blood transfusion, transfusion-related immune modulation (TRIM), ubiquitin, melanoma, metastasis

\section{Introduction}

Ubiquitin is an immunophilin [1,2] that plays a vital role in immune homeostasis.[3] The ubiquitin peptide fragment (U50-59) has been demonstrated to significantly inhibit both cellular immunity and humoral immunity.[4] Moreover, extracellular ubiquitin has positive therapeutic effects on certain autoimmune diseases, organ transplantation, and infectious and noninfectious diseases. $[5,6]$

Allogeneic blood transfusion, which has a history of nearly 500 years, is a clinical treatment 
method that involves the transfer of red blood cells (RBCs) from donor to recipient.[7] The storage duration of blood has been lengthened to 42 days at $4^{\circ} \mathrm{C}$ since the improvement of storage conditions in the 1940s.[8] According to statistics, the annual consumption of RBCs has reached 90 million units.[8] In some countries, blood transfusion therapy is even more common than the use of drugs.[9] Although clinical transfusion is safer and more effective than before, numerous studies have confirmed that transfusion can lead to severe transfusion-related immune modulation (TRIM) responses,[10-13] such as incompatibility issues, coagulopathy, allergic reactions, multiple organ failure, increased rate of recurrence after tumor resection, postoperative infection and long-term mortality. Furthermore, blood transfusion can elicit an inflammatory response, which inhibits the body's immune function, and leads to the imbalance in the ratio of TH1/TH2 cells, with bias towards the proliferation of $\mathrm{TH} 2$-inducing tumorigenic cytokines and decrease in anti-tumor TH1-inducing cytokines.[14, 15] Leukocytes present in whole blood have been assumed to promote TRIM. However, the immunoregulatory effects remained intact even after their removal from the transfused blood.[16, 17] Therefore, this indicates that other components in stored blood also contribute to immune regulation.

Perioperative blood transfusion has been reported to be closely correlated with tumor recurrence in colorectal cancer and hepatocellular carcinoma. $[18,19]$ The storage duration and infusion volume of $\mathrm{RBCs}$ are both potential factors that contribute to tumor recurrence.[19-21] It is noteworthy that the infusion of stored blood has been reported to increase the risk of tumor recurrence and mortality in many cancers and carcinomas.[22-26] Furthermore, blood storage duration has been confirmed as one of the harmful factors, and the infusion of aged RBCs has been observed to promote the spread of tumors.[20] The morphology, function, biochemistry and other aspects of blood in the storage process have changed, and these changes became more pronounced with longer storage duration. $[7,27]$ The ubiquitin content in RBCs is $1000-10000$ times of that in other blood cells.[28-30] During the storage process of whole blood, ubiquitin in RBCs is released into plasma, resulting in the increase of extracellular ubiquitin. It was found that the ubiquitin content increased by nearly 40 -fold in whole blood stored for 35 days,[31, 32] suggesting that ubiquitin concentration gradually increases during blood storage, and that it may be one of the key factors that causes a series of side effects after transfusion.
Existing methods to prolong the storage duration of RBCs cannot prevent their damage on storage. The underlying causes for these adverse consequences that result from the use of stored blood for transfusion remain poorly understood. One possible cause is the change in the structure and function of RBCs on storage in response to changes in metabolism, oxidative stress and erythrocyte membrane damage. $[7,8]$ Inflammation that resulted from the excessive release of iron in response to erythrocyte membrane rupture[33] and the release of a substantial amount of extracellular ubiquitin from RBC in stored blood[31] have been reported to be associated with adverse clinical reactions after blood transfusion. In a previous study, it was revealed that extracellular ubiquitin released in stored blood promoted the mRNA expression of TH2 cytokines in peripheral blood mononuclear cells.[32] Moreover, extracellular ubiquitin was found to bind to the surface of Treg cells, thereby enhancing the immunosuppressive activity of regulatory $\mathrm{T}$ cells.[34] The binding of exogenous ubiquitin to CXCR4 receptors[35] can promote lung metastasis in mice with acute pneumonia.[36] Thus, it was hypothesized that extracellular ubiquitin in stored blood may play a role in immunosuppression, thereby promoting tumor metastasis in recipients of blood transfusion therapy.

\section{Methods}

\section{Animal handling and care}

Wild-type male C57BL/ 6 mice (SPF, eight weeks old) were purchased from the Shanghai Research Center for Southern Model Organisms (Shanghai, China). These mice were habituated under vivarium conditions for one week before the start of the intervention procedures. All experiments were approved by the Institutional Animal Care and Use Committee of Huashan Hospital, Fudan University, China.

\section{Collection and storage of mouse blood and measurement of ubiquitin concentration}

Fifty-ml conical tubes containing $4.2 \mathrm{ml}$ of CPDA-1 directly obtained from human blood storage bags (Blood Center of Shanghai, China) were used, which contained blood drawn from the eyeballs of eight-week-old male wild-type C57BL/6 mice anesthetized with halothane. A total of $30 \mathrm{ml}$ of whole blood (approximately 500-800 $\mu \mathrm{l}$ of blood from each mouse) was obtained from 40-50 mice, and collected in a conical tube with approximately $14 \%$ final CPDA-1 concentration. Then, a high-efficiency neonate leukocyte reduction filter was used to remove 
leukocytes. The leukocyte-removed blood was centrifuged at $400 \mathrm{~g}$ for 15 minutes at $4^{\circ} \mathrm{C}$, and the supernatant was partially removed to obtain a hematocrit of approximately $75 \%$. The collected blood was distributed into $201.5-\mathrm{ml}$ EP tubes, with each tube containing $1 \mathrm{ml}$ of blood. These 20 tubes were randomly divided into four groups, in which five tubes were assigned for each group. All tubes were sealed and stored at $4^{\circ} \mathrm{C}$ in the dark. Next, the tubes in the four groups were centrifuged at day $0,5,10$ and 15 , respectively. Then, the plasma obtained was stored at $-80^{\circ} \mathrm{C}$ for testing. The ubiquitin concentration in whole blood was detected using an ELISA kit (F11702, Westtang Biotechnology, Shanghai, China), which specifically detected recombinant or native mouse mono-ubiquitin, rather than poly-ubiquitin proteins.

\section{Cell lines and cell culture}

The murine melanoma cell line B16, which stably expresses luciferase (B16-luciferase), and the enhanced expressing green fluorescent protein (EGFP) cell line (B16-EGFP) were purchased from the Shanghai Research Center for Southern Model Organisms (Shanghai, China). All cell culture reagents were obtained from Gibco-BRL (Gibco BRL, Grand Island, NY, USA). The B16 cell line was maintained in DMEM media supplemented with $10 \%$ heat-inactivated fetal bovine serum (FBS) and 1\% penicillin-streptomycin at $37^{\circ} \mathrm{C}$ in a humidified incubator with $5 \% \quad \mathrm{CO}_{2}$. At approximately $80 \%$ confluence, cells were trypsinized and washed three times with phosphate-buffered saline (PBS).

\section{Cell proliferation and invasion assays}

Cell proliferation assay was performed using Cell Counting Kit-8 (Dojindo, Kumamoto, Japan). The B16 cell line was cultured in 96 -well plates $\left(5 \times 10^{3}\right.$ cells/well) and treated with exogenous recombinant human ubiquitin (4841-100; BioVision, Milpitas, CA, USA) at the tested concentrations $(200 \mathrm{ng} / \mathrm{ml}, 400$ $\mathrm{ng} / \mathrm{ml}$, and $800 \mathrm{ng} / \mathrm{ml}$ ) for 24, 48, 72 and 96 hours, respectively. The absorbance of each well was measured at a wavelength of $450 \mathrm{~nm}$ (OD 450). Cell invasion was performed using the Transwell assay (Corning, NY, USA). The filters of the Transwell chambers were pre-coated with Matrigel (BD Bioscience, San Jose, CA, USA). Then, $5 \times 10^{3} / 100 \mu \mathrm{l}$ of B16 cells were loaded to the upper chamber, while 600 $\mu 1$ of $20 \%$ FBS was added to the lower chamber. Subsequently, $100 \mu \mathrm{l}$ of DMEM, and $400 \mathrm{ng} / \mathrm{ml}, 800$ $\mathrm{ng} / \mathrm{ml}$ and $1600 \mathrm{ng} / \mathrm{ml}$ of extracellular ubiquitin were added separately to the upper chamber. After at least 24 hours, cells that invaded through the basement membrane were fixed in paraformaldehyde, stained by crystal violet, and counted under a light microscope at a magnification of $\times 200$. Six fields were counted per sample. The preparation of the ubiquitin stock solution and cell function experiments were all performed in a sterile environment.

\section{Experiment grouping and tumor metastasis model}

An experimental metastasis model of melanoma in mice was established via lateral tail vein injection.[37, 38] B16, B16-luciferase and B16-EGFP cell lines were used in the present study. One hundred $\mu \mathrm{l}$ of PBS-diluted cells at $5 \times 10^{6} / \mathrm{ml}$ concentration were injected into each mouse via the lateral tail vein. Mice were sacrificed on the $1^{\text {st }}$ and $21^{\text {st }}$ day after blood transfusion. The groupings were as follows: control group, physiological saline; experimental group one, D0 (fresh blood stored for zero days); experimental group two, D15 (whole blood stored for 15 days); experimental group three, D0 + 320 ng (fresh blood containing $320 \mathrm{ng}$ of ubiquitin); experimental group four, D0 + $3200 \mathrm{ng}$ (fresh blood containing $3200 \mathrm{ng}$ of ubiquitin). For experimental groups three and four, exogenous sterile ubiquitin (U5507; Sigma-Aldrich, St. Louis, MO, USA) was added to supplement the $64 \mathrm{ng}$ of endogenous ubiquitin in fresh blood. Mice have approximately 1.5 $\mathrm{ml}$ of blood. Tail vein injection was performed at a 200 $\mu \mathrm{l}$-scale for three times in total, at 24-hour intervals, and $320 \mathrm{ng}$ and $3200 \mathrm{ng}$ of ubiquitin in a $200-\mu \mathrm{l}$ scale were used to simulate the small and massive clinical transfusion, respectively. The preparation of the ubiquitin stock solution and mice tail vein transfusion experiments were performed on a super-clean bench.

\section{Flow cytometry}

The blood drawn from eyeballs removed from anesthetized mice was centrifuged for 15 minutes at $300 \times \mathrm{g}$. Then, the supernatant was stored at $-80^{\circ} \mathrm{C}$ for subsequent analysis using a FACSCanto II flow cytometer (BD Biosciences, San Jose, CA, USA). Cytokines, such as interleukin (IL)-1 $\beta$, IL-6, IL-10, IL-12, interferon- $\gamma$ (IFN- $\gamma)$ and tumor necrosis factor- $\alpha$ (TNF- $\alpha$ ), were quantified using a Cytometric Bead Array Mouse Flex Kit (BD Biosciences, San Jose, CA, USA). Annexin V-PE/ 7-AAD Apoptosis Detection Kit (BD Biosciences, San Jose, CA, USA) was used to identify and quantify apoptotic cells on a single-cell basis by flow cytometry, which contained Annexin V labeled with PE and 7-AAD. Simultaneous staining of cells with Annexin V-PE and the non-vital dye 7-aminoactinomycin $\mathrm{D}$ (7-AAD) allowed the discrimination of intact cells (Annexin V-PE negative, 7-AAD negative), early apoptotic (Annexin V- PE 
positive, 7-AAD negative) and late apoptotic or necrotic cells (Annexin V- PE positive, 7-AAD positive). $10 \times 10^{4}$ cells were collected by flow cytometry in this experiment. The data obtained was analyzed using the FlowJo software (FlowJo, LLC, USA).

\section{Tumor cell in vivo dissemination assay}

EGFP-expressing B16 $\left(5 \times 10^{5}\right.$ cells $)$ was introduced in C57BL/ 6 male mice (eight weeks old) via tail vein injection using the same procedure described above, and ubiquitin (320 ng and $3200 \mathrm{ng}$ ) was administered for three times at 24-hour intervals. Mice were sacrificed at 24 hours after the administration of the third ubiquitin dose. Then, the lungs were perfused with PBS to remove the blood, the left lung tissues were cryopreserved with liquid nitrogen for protein detection, and the right lung tissues were embedded with OCT compound for the preparation of frozen sections, which were approximately $10 \mu \mathrm{m}$ thick. EGFP-expressing cells, hematoxylin and eosin (H\&E) staining and immunohistochemical sections were visualized using an EVOS digital inverted fluorescence microscope (Olympus, Tokyo, Japan).

\section{Luciferase assay}

Tumor-bearing male C57BL/ 6 mice anesthetized with halothane were injected at the tail vein with the melanoma cell line B16 to stably express luciferase. The mice were randomly divided into three groups: control group, mice were injected with saline; $320 \mathrm{ng}$ and $3200 \mathrm{ng}$ extracellular ubiquitin (Sigma, USA) intervention groups. Tail vein injections were performed for three times at 24-hour intervals. Luciferase activity (photons per second) was monitored using a real-time imaging system on the $9^{\text {th }}, 14^{\text {th }}$ and $19^{\text {th }}$ day after B16 tumor cell inoculation, and was quantified using the Living Image software (Roper Scientific, USA).

\section{Western blotting}

Western blotting was performed according to an established protocol.[39] Protein concentration was measured using a BCA protein assay kit (Beyotime, Shanghai, China). Thirty $\mu$ g of protein per sample was probed with primary antibodies MMP-9 and VEGF (Cell Signaling Technology, Danvers, MA, USA), and the secondary antibody (Abcam, Cambridge, MA, USA). $\beta$-actin was used as a loading control (Beyotime, Shanghai, China).

\section{Hematoxylin and eosin staining and immunohistochemistry}

The immunohistochemical examination of frozen sections were prepared and visualized through a light microscope (Olympus, Tokyo, Japan) using a standard protocol.[39, 40] Fresh lung tissues obtained from mice sacrificed on the $21^{\text {st }}$ day after transfusion were embedded with OCT, and frozen at $-80^{\circ} \mathrm{C}$ before H\&E staining. Primary antibodies against tumor markers, including HMB-45 (Cell Signaling Technology, Danvers, MA, USA), MMP-9 (Cell Signaling Technology, Danvers, MA, USA), VEGF (Cell Signaling Technology, Danvers, MA, USA), and Ki-67 (Cell Signaling Technology, Danvers, MA, USA), and the secondary antibody (Abcam, Cambridge, MA, USA) were used.

\section{Statistical analysis}

Statistical analysis was performed using the Stata 11.0 software (STATA, USA). For data that assumed a normal distribution, comparison studies were conducted using Student's t-test (between two groups) and variance analysis (among all groups). Otherwise, the analyses of independent groups were performed using the non-parametric Wilcoxon signed-rank test. Survival analysis was performed using Kaplan-Meier survival curves and log-rank tests. A $P$-value $<0.05$ in the two-tailed test was considered statistically significant.

\section{Results}

\section{Extracellular ubiquitin promotes the proliferation and invasion of melanoma cells and reduces their apoptosis in mice}

All concentrations of ubiquitin that were tested (200 ng/ml, $400 \mathrm{ng} / \mathrm{ml}$ and $800 \mathrm{ng} / \mathrm{ml}$ ) promoted the proliferation and invasion of melanoma cells, with 400 $\mathrm{ng} / \mathrm{ml}$ of ubiquitin exhibiting the strongest effect (Figs. 1B-1C). Next, flow cytometry was performed to assess the effect of $400 \mathrm{ng} / \mathrm{ml}$ of ubiquitin on the apoptosis of melanoma cells, and a significant reduction was observed in both the early and late apoptosis of these cells (Fig. 1D).

\section{Infusion of stored blood promotes lung tumor metastasis in melanoma mice model}

On the $21^{\text {st }}$ day after the infusion of stored blood into tumor-bearing mice, lung tissues were harvested and analyzed. Lung tissues for the D15 (blood stored for 15 days) group weighed $0.2 \pm 0.03 \mathrm{~g}$, which was significantly higher than lung tissues for the control group (weighed: $0.13 \pm 0.01 \mathrm{~g}$ ), while lung tissues for the D0 (fresh whole blood) group weighed $0.14 \pm 0.01$ g $(P<0.001$, Fig. 2B). In addition, the number of metastatic nodules on the surface of lung tissues for the D15 group was $26.50 \pm 10.60$, which was significantly higher, when compared to that for the control group $(4.33 \pm 2.80)$ and D0 group $(7.83 \pm 2.23)$ $(P<0.01$, Fig. 2C). In addition, the number of tumor 
metastases for the D15 group was observed to be higher than those for the control and D0 groups by H\&E staining $(P<0.01, \quad$ Figs. 2D-2E). The mmunohistochemistry experiments revealed that the expression levels of tumor markers HMB-45, MMP-9, VEGF and Ki-67 in the D15 group were significantly higher than those in the D0 and control groups (Fig. 3A). Furthermore, higher expression levels of MMP-9 and VEGF were observed in the D15 group by western blotting (Fig. 3B).

\section{Extracellular ubiquitin in stored blood promotes tumor progression and reduces the long-term survival rate of tumor-bearing mice}

The positive correlation between the ubiquitin concentration in stored human blood preparations

and storage duration was previously observed by the investigators of this study. ${ }^{32}$ Indeed, the experiment conducted in the present study that assessed the ubiquitin content in mice whole blood stored for 0,5 , 10 and 15 days, respectively, confirmed this earlier finding (Fig. 1A).

Two ubiquitin intervention groups administered with either $320 \mathrm{ng}$ or $3200 \mathrm{ng}$ of extracellular ubiquitin, which were equivalent to ubiquitin content in 1 and 10 units of whole blood stored for 15 days, respectively, were used to investigate its effect on the early lung migration of mouse melanoma cells. A significant increase in the number of EGFP-labeled melanoma cells in lung of tumor-bearing mice was observed on the first day after the administration of three doses of ubiquitin, when compared to the

C

A

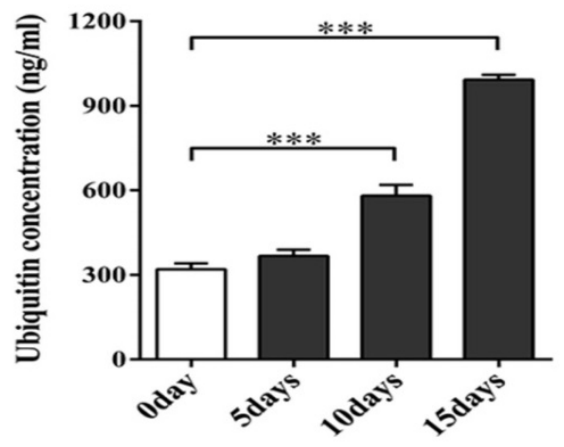

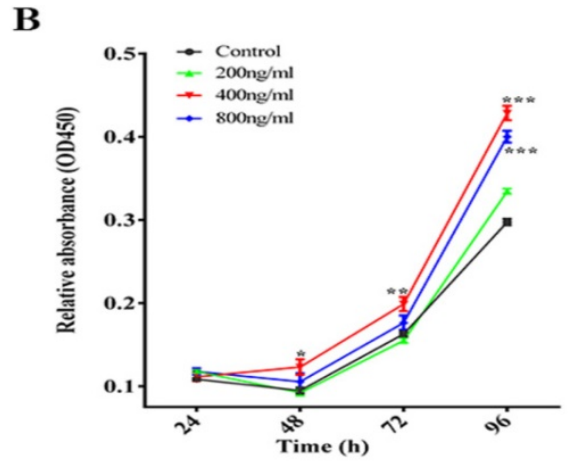

B
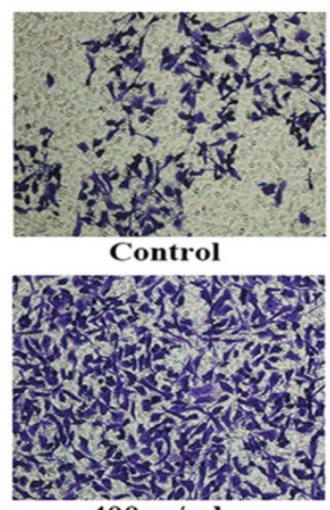

$\mathbf{D}$


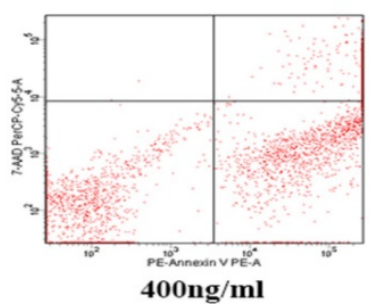

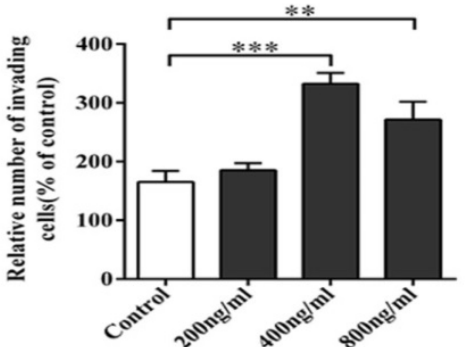

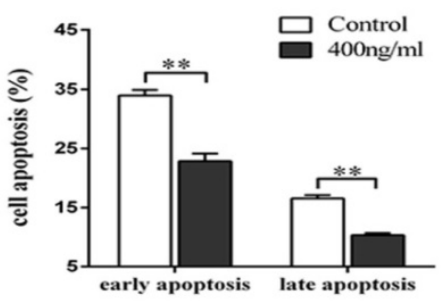

Fig. 1. The ubiquitin concentration in RBC enriched plasma of mice increases with prolonged storage, and affects the biological functions of melanoma cells. (A) Ubiquitin concentration in whole blood stored for $0,5,10$ and 15 days was measured using a mouse ubiquitin ELISA kit ( $n=5)$. (B) The effect of ubiquitin concentrations ( $200 \mathrm{ng} / \mathrm{ml}, 400$ $\mathrm{ng} / \mathrm{ml}$ and $800 \mathrm{ng} / \mathrm{ml}$ ) on the proliferation of melanoma cells was assessed using a CCK-8 kit. (C) Transwell assay was performed to determine the effect of different ubiquitin concentrations $(200 \mathrm{ng} / \mathrm{ml}, 400 \mathrm{ng} / \mathrm{ml}$ and $800 \mathrm{ng} / \mathrm{ml}$ ) on the invasion of melanoma cells. (D) The effect of $400 \mathrm{ng} / \mathrm{ml}$ of ubiquitin on the early and late apoptosis of melanoma cells were assessed by flow cytometry. Data from three independent experiments were expressed as mean \pm standard error of the mean (SEM). * represents a $P$-value of $<0.05$; ** represents a $P$-value of $<0.01$; *** represents a $P$-value of $<0.001$. 
control group without extracellular ubiquitin $(P<0.01$, Fig. 4A). Furthermore, H\&E staining for the control group revealed that the alveolar structure of lung tissues of tumor-bearing mice was intact, and neither was there congestive edema in the pulmonary interstitium, nor inflammation. Conversely, the destruction of the alveolar structure, alveolar septum fracture, pulmonary interstitial congestion and inflammation were observed in these two ubiquitin intervention groups. The significant upregulation of tumor markers HMB-45, MMP-9, VEGF and Ki-67 were observed by immunohistochemical staining in the ubiquitin intervention groups (Fig. 4B). Moreover, MMP9 and VEGF protein expression levels were observed to significantly increase in the ubiquitin intervention groups by immunoblotting (Fig. 4C).

Real time fluorescence imaging was used to monitor the melanoma metastases in tumor-bearing mice, and the changes in long-term survival and weight were recorded. It was found that $320 \mathrm{ng}$ of ubiquitin promoted the lung and systemic metastasis of melanoma cells on the $9^{\text {th }}, 14^{\text {th }}$ and $19^{\text {th }}$ days, while $3200 \mathrm{ng}$ of ubiquitin exhibited an obvious effect in promoting metastasis on the $19^{\text {th }}$ day $(P<0.05$, Figs. $5 \mathrm{~A}-5 \mathrm{~B})$. The rate of weight gain in tumor-bearing mice in the 3200 ng ubiquitin intervention group decreased on the $19^{\text {th }}$ and $20^{\text {th }}$ days $(P<0.05$, Fig. 5 C). Moreover, the survival rate of tumor-bearing mice for both ubiquitin intervention groups significantly decreased by $37.50 \%$ and $28.75 \%$, when compared to controls. The 320 ng ubiquitin group had the lowest survival rate $(P<0.01$, Fig. $5 \mathrm{D})$.

\section{Ubiquitin in stored blood promotes the expression of markers for tumor cell proliferation and metastasis in lung tissues of tumor-bearing mice}

The expression of markers for tumor cell proliferation and metastasis in lung tissues obtained from tumor-bearing mice in the two ubiquitin intervention groups, D0+320 ng and D0+3 $200 \mathrm{ng}$, was monitored by immunohistochemistry. On the $21^{\text {st }}$ day after transfusion, markers for metastasis and proliferation in lung tissues (HMB-45, MMP-9, VEGF and $\mathrm{Ki}-67)$ were detected by immunohistochemistry and western blotting. Compared to the control and D0
A

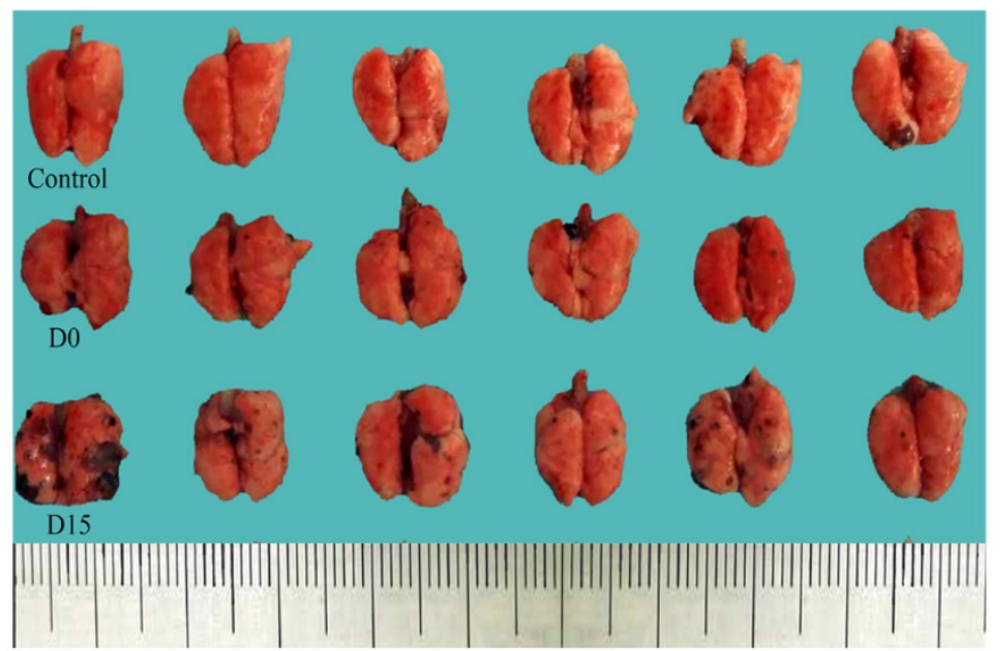

D

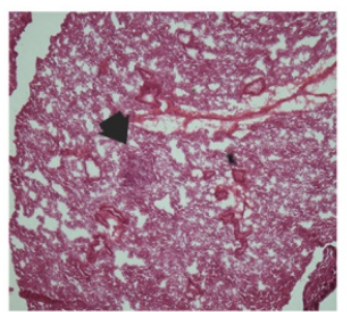

Control

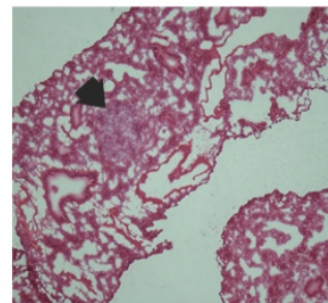

D0

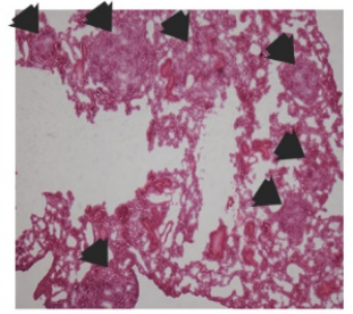

D15
B
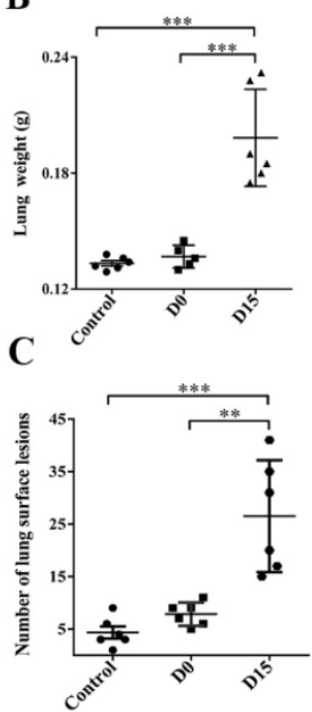

$\mathbf{E}$

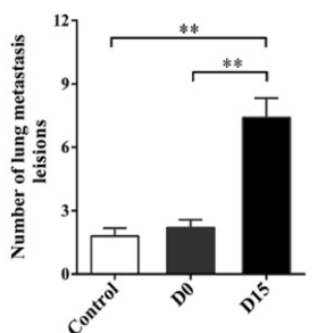

Fig. 2. The transfusion promotes melanoma metastasis in the lungs of tumor-bearing mice. (A) Fresh lung tissues of tumor-bearing mice in the control group, D0 group and D 15 group on the $21^{\text {st }}$ day after transfusion ( $n=6$ in each group). (B) The relative weight of lung tissues in tumor-bearing mice in the control, D0 and D 15 groups on the $21^{\text {st }}$ day after transfusion. (C) Statistical analyses of tumor numbers on the surface of lung tissues in tumor-bearing mice in the control, D0 and D15 groups on the 21 st day after transfusion. (D) H\&E staining of lung pathological sections of tumor-bearing mice in the control, D0 and D15 groups on the 21 st day after transfusion (original magnification $\times 100$ ). (E) The relative number of metastatic lesions in lung tissues of tumor-bearing mice in the control, D0 and D15 groups on the 21 st day after transfusion. Data from three independent experiments were expressed as mean \pm standard error of the mean (SEM). ** indicates a $P$-value of $<0.01$; *** indicates a $P$-value of $<0.001$. 
groups, there was a significant increase in the expression of tumor markers tested in both ubiquitin intervention groups. Among these groups, tumor markers in the D0+320 ng group had the highest expression levels (Fig. 6A). Similarly, elevated expression levels of MMP-9 and VEGF tumor markers in the D0+320 ng and D0+3 $200 \mathrm{ng}$ ubiquitin intervention groups were observed by western blotting, and these expression levels were highest in the former group (Fig. 7B).

\section{Extracellular ubiquitin promotes TH2 proliferation in the peripheral blood of tumor-bearing mice}

The expression levels of $\mathrm{TH} 1$ and $\mathrm{TH} 2$ cytokines (IL-1, IL-12, TNF- $\alpha$, INF- $\gamma$, IL-6 and IL-10) in the peripheral blood of tumor-bearing mice collected on the $1^{\text {st }}$ and $21^{\text {st }}$ day after transfusion with either ubiquitin-containing stored blood or fresh blood were assessed by flow cytometry. Only TNF- $\alpha$ and INF- $\gamma$ (TH1 cytokines), and IL-6 (TH2 cytokines) could be detected.
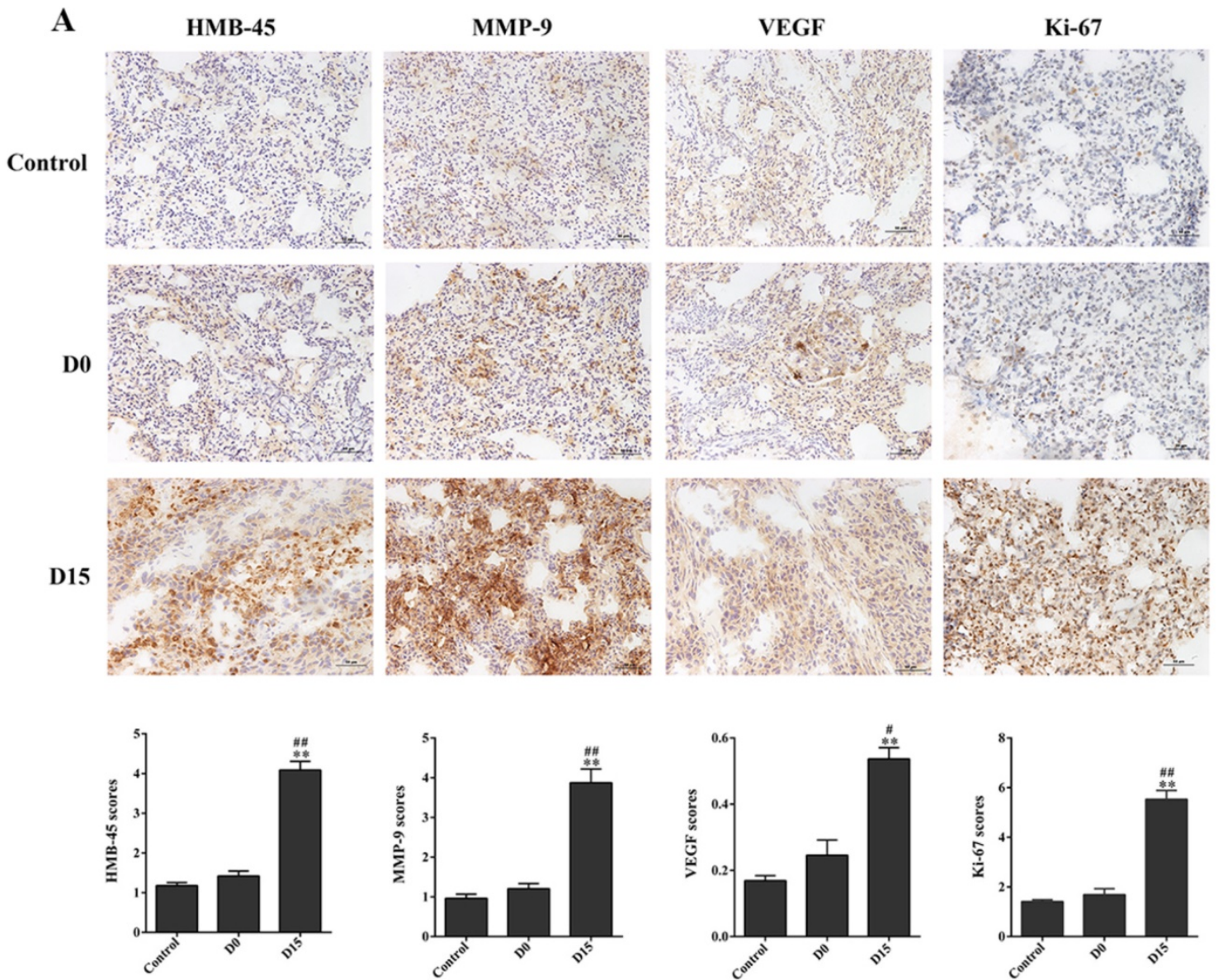

B
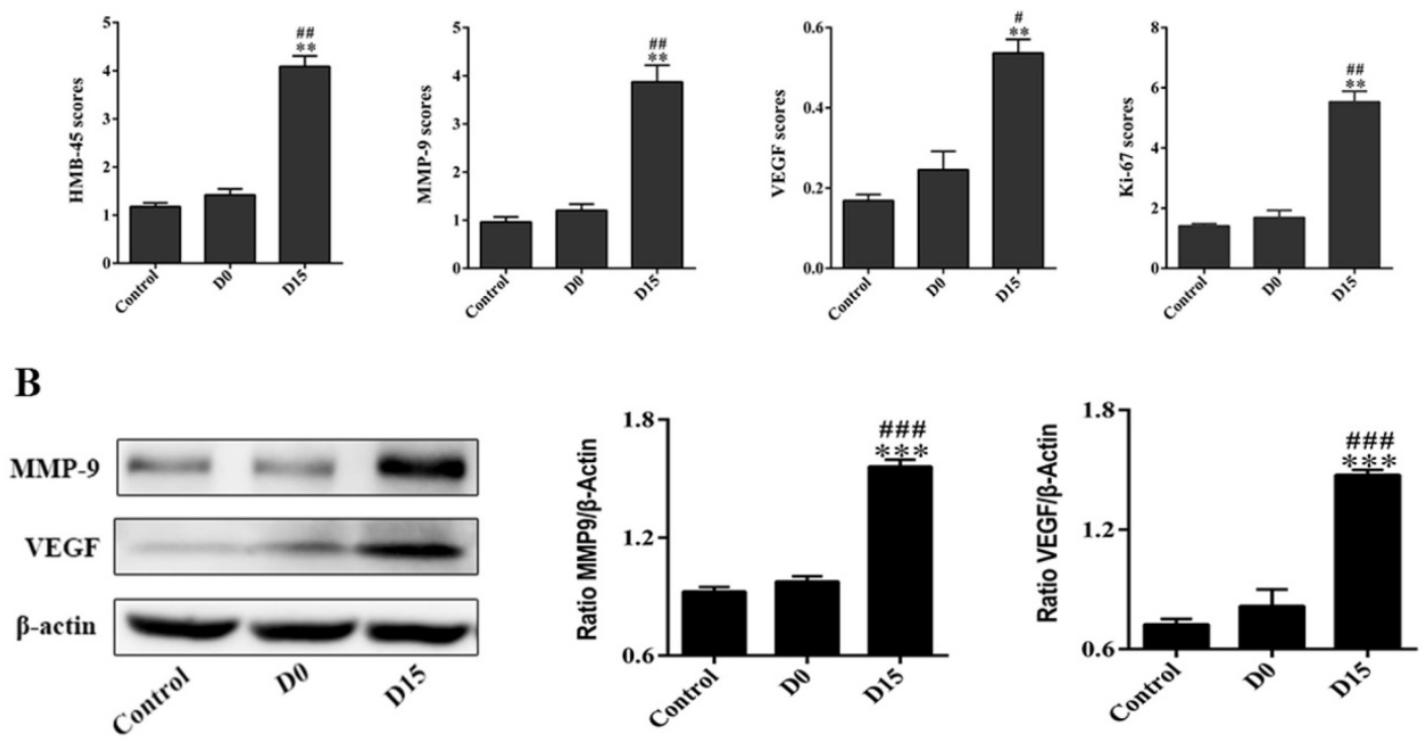

Fig. 3. The transfusion promotes the expression of markers associated with tumor metastasis and proliferation in lung tissues of tumor-bearing mice. (A) The immunohistochemistry of lung tissues obtained from tumor-bearing mice after transfusion. The infusion of whole blood stored for 15 days upregulated the expression levels of HMB-45, MMP-9, VEGF and Ki-67 tumor markers in lung tissues of tumor bearing mice (original magnification $\times 200$; scale bar $=100 \mu \mathrm{m}$ ). (B) Western blotting of lung tissues of tumor-bearing mice after transfusion. The expression levels of MMP-9 and VEGF in the D15 group were obviously higher than those in the control group and D0 group. Data was expressed as mean \pm standard error of the mean (SEM) of three independent experiments. Compared with the control group, $*$ represents a $P$-value of $<0.05$, $* *$ represents a $P$-value $<0.01$, *** represents a $P$-value of $<0.001$; compared with the D0 group, \# represents a $P$-value of $<0.05$, \#\# represents a $P$-value of $<0.01$, \#\# represents a $P$-value of $<0.001$. 
A
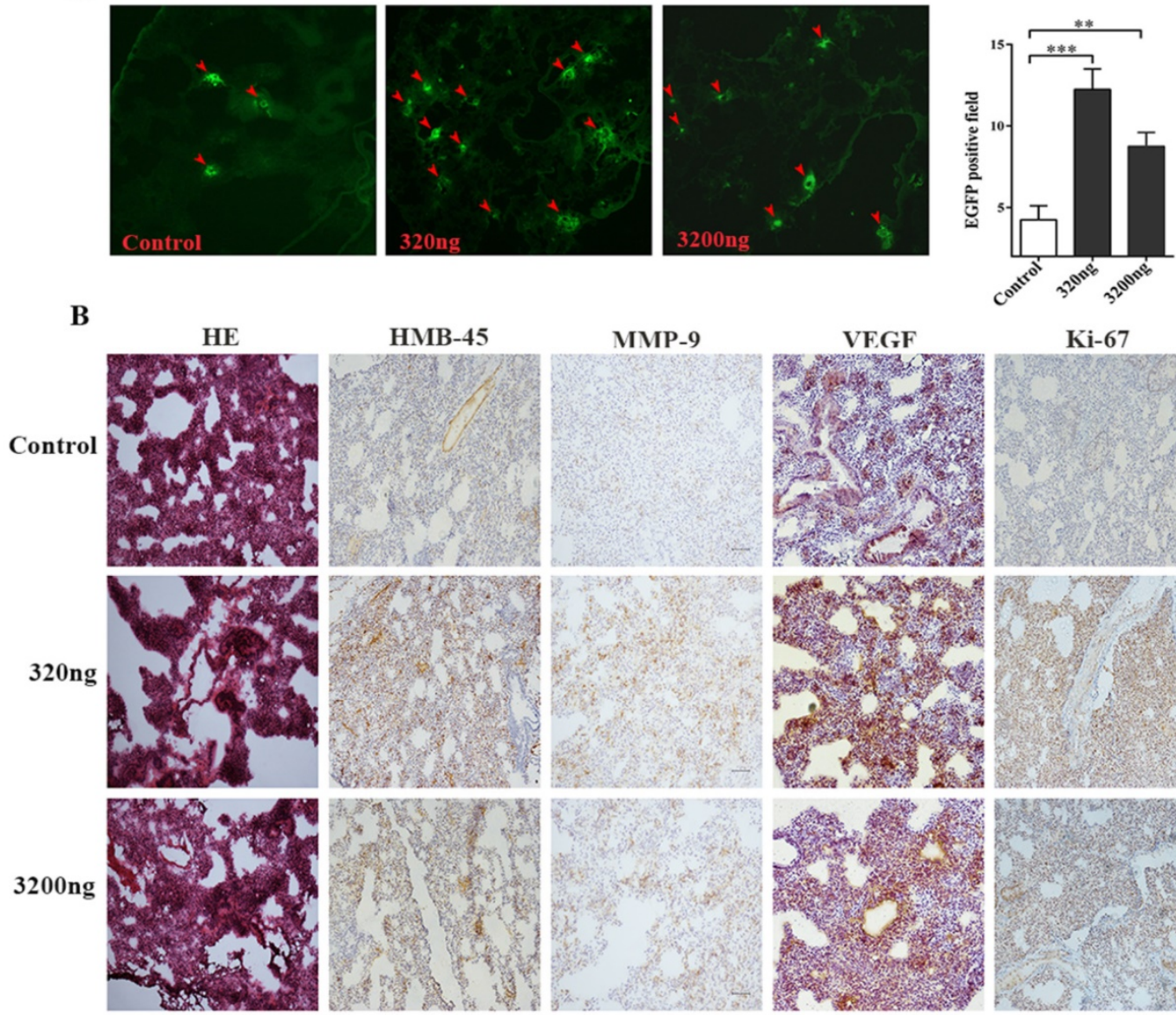

HMB-45

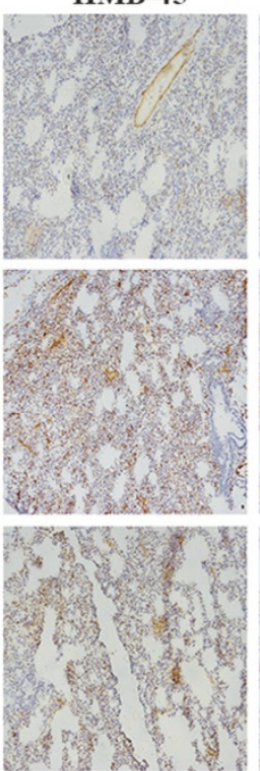

MMP-9

VEGF
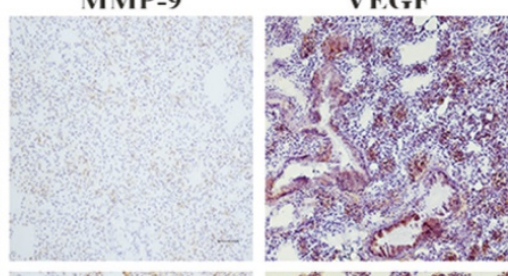

Ki-67

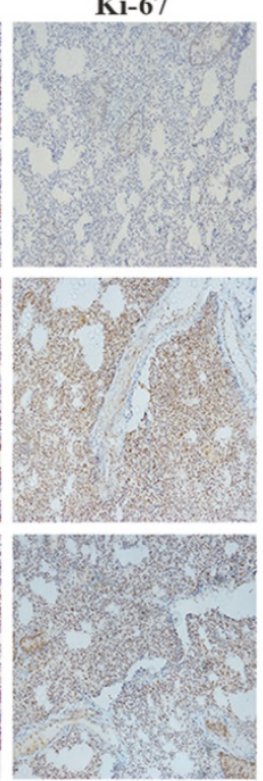

$$
\text { C }
$$
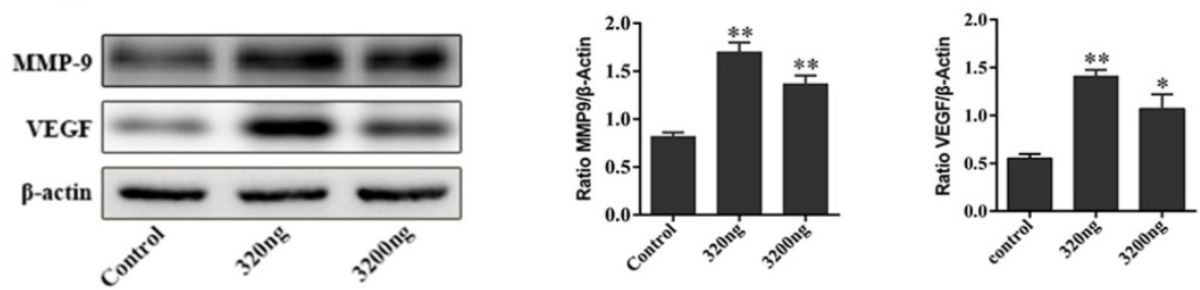

Fig. 4. Ubiquitin promotes the early migration of melanoma cells in lungs of tumor-bearing mice. (A) Left: Images of frozen lung sections in the two intervention groups ( 320 $\mathrm{ng} / 200 \mu \mathrm{l}$ and $3200 \mathrm{ng} / 200 \mu \mathrm{l})$ of mice subjected to tail vein injection with EGFP-B16 tumor cells $\left(5 \times 10^{5 / 100 \mu l)}\right.$ and the three consecutive addition of ubiquitin at 24-hour intervals. Arrow: The expression of EGFP-positive tumor cells visualized by fluorescence microscopy (original magnification x 100). Right: Quantitative analysis of the number of EGFP-positive tumor cells in each field ( $n=6$, each group). (B) The immunohistochemistry of H\&E stained lung tissues on the first day after three consecutive ubiquitin interventions (the original magnification of $\mathrm{H} \& \mathrm{E}$ staining was $\times 40$, and the original magnification for immunohistochemistry was $\times 200$ ). (C) The western blotting of lung tissues of tumor-bearing mice after three consecutive rounds of ubiquitin intervention. It was observed that the expression levels of MMP-9 and VEGF in the two ubiquitin intervention groups were higher than the levels in the control group. Data from three independent experiments were expressed as mean \pm standard error of the mean (SEM). ** represents a $P$-value $<0.01$; *** represents a $P$-value $<0.001$.

The observed ratio of TH1/TH2 cytokines in the two ubiquitin intervention groups infused with fresh blood was similar with that in the D15 group (Figs. 7A-7B). However, TH1 cytokine INF- $\gamma$ expression was reduced and TH2 cytokine IL-6 expression increased in the peripheral blood of both groups of tumor-bearing mice infused with ubiquitincontaining stored blood and fresh blood, respectively, when compared to the control and D0 groups, indicating a bias towards $\mathrm{TH} 2$ cytokines. The observed increase in TNF- $\alpha$ expression on the $21^{\text {st }}$ day after transfusion may be due to tumor metastasis.

\section{Ubiquitin present in stored blood reduces the percentage of $T$ cells and NK cells and reduces the $C D 4^{+} T / C D 8^{+} T$ ratio in the peripheral blood of tumor-bearing mice}

Flow cytometry was used to study the effect of ubiquitin in stored blood on immunocytes, T cells, B cells and NK cells in tumor-bearing mice on the $1^{\text {st }}$ and $21^{\text {st }}$ day after transfusion. A similar downtrend in the percentage of $\mathrm{T}$ and $\mathrm{NK}$ cells on the $1^{\text {st }}$ and $21^{\text {st }}$ day after transfusion was observed (Fig. 7C). Furthermore, there was a lower percentage of $\mathrm{CD}^{+} \mathrm{T}$ 
cells in the D15 group, when compared to the control group and D0 group. Similarly, the percentage of NK cells in the D15 group was significantly lower than that in the control group. However, there was no significant difference in the percentage of B cells at both the $1^{\text {st }}$ and $21^{\text {st }}$ day after transfusion among all three groups (control, D0 and D15 groups). The $\mathrm{CD} 4^{+} \mathrm{T} / \mathrm{CD}^{+} \mathrm{T}$ ratios on the $1^{\text {st }}$ and $21^{\text {st }}$ days after transfusion in the D15 group were both lower than those in the control and D0 groups.

The percentages of $\mathrm{CD}^{+} \mathrm{T}$ cells in the $\mathrm{D} 0+320 \mathrm{ng}$ group on the $1^{\text {st }}$ day and D $0+3200 \mathrm{ng}$ group on the $21^{\text {st }}$ day were significantly lower than those in the control and D0 groups (Fig. 7D). In addition, there was a significantly lower percentage of NK cells in the D0+3 200 ng group, when compared to that in the control and D0 groups on the $21^{\text {st }}$ day. Meanwhile, there was no significant difference in the percentage of $B$ cells in the D0+3 200 ng group between the $1^{\text {st }}$ day and $21^{\text {st }}$ day after transfusion. For the D0+320 ng group on the $1^{\text {st }}$ day and D0+3 $200 \mathrm{ng}$ group on the $21^{\text {st }}$ day, the $\mathrm{CD} 4^{+} \mathrm{T} / \mathrm{CD} 8^{+} \mathrm{T}$ ratios were both lower than those in the control and D0 groups.

\section{Discussion}

Although the effective storage time of blood has been greatly lengthened with the advances in modern medical technology, adverse consequences, such as transfusion-related immune modulation (TRIM) responses, arising from the transfusion of stored blood in cancer patients has become a growing concern. Using a melanoma mouse model and a variety of cell biology techniques, such as real time imaging, immunohistochemistry and flow cytometry, the association between ubiquitin content in stored blood and the proliferation, invasion and apoptosis of melanoma cells in mice was established (Figs. 2-6). Hence, the present findings suggest the novel role of ubiquitin present in stored blood in immune modulation, and as a determinant for the poor clinical prognosis of cancer patients.

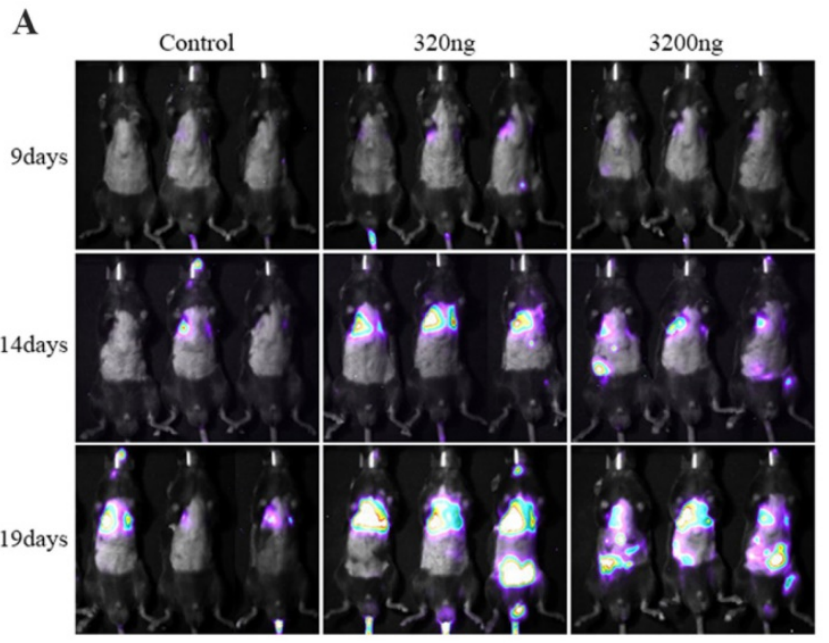

B

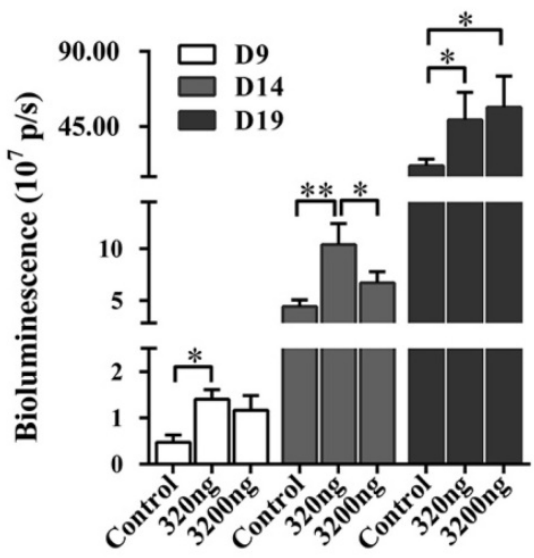

C

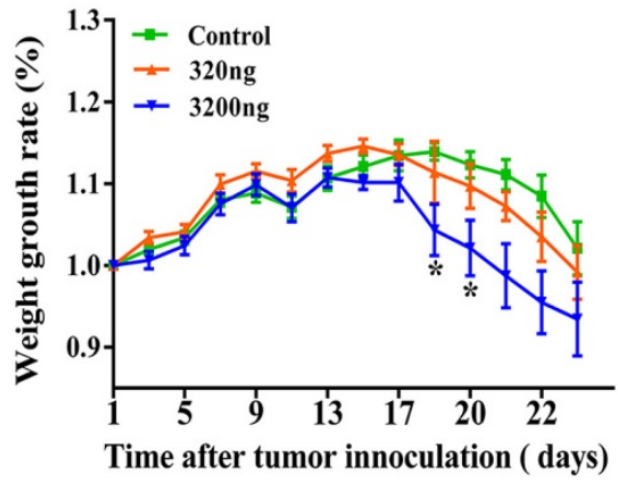

D

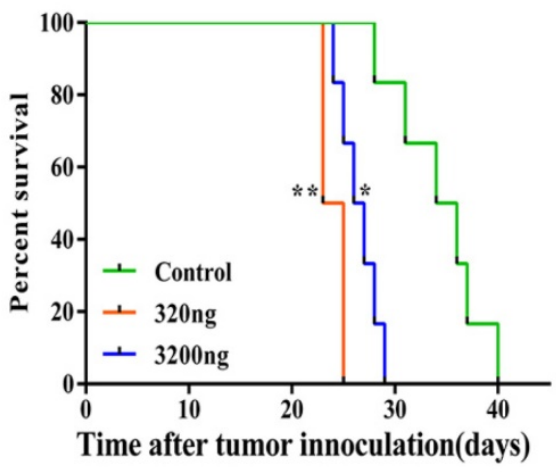

Fig. 5. Effects of ubiquitin on tumor metastasis, body weight and survival rate in tumor-bearing mice. (A) B16-luciferase cells $\left(5 \times 10^{5}\right)$ were inoculated into the tail vein of mice, and these mice were randomly divided into three groups (n=6, each group): intraperitoneally injected with $200 \mu$ l of normal saline, $320 \mathrm{ng}$ of ubiquitin and $3200 \mathrm{ng}$ of ubiquitin, respectively. The luciferase activity of tumor cells was monitored by real-time imaging on the 9 th, 14 th and 19 th day after inoculation. (B) The statistical analysis of in vivo luciferase activity. (C) The analysis of the rate of weight gain in each group of tumor-bearing mice. (D) Log-rank survival analysis of tumor-bearing mice in the three groups (control, 320 $\mathrm{ng}$ and $3200 \mathrm{ng}$ ubiquitin intervention groups). Data obtained from three independent experiments were expressed as mean \pm standard error of the mean (SEM). $*$ represents a $P$-value of $<0.05$; ** represents a $P$-value of $<0.01$. 


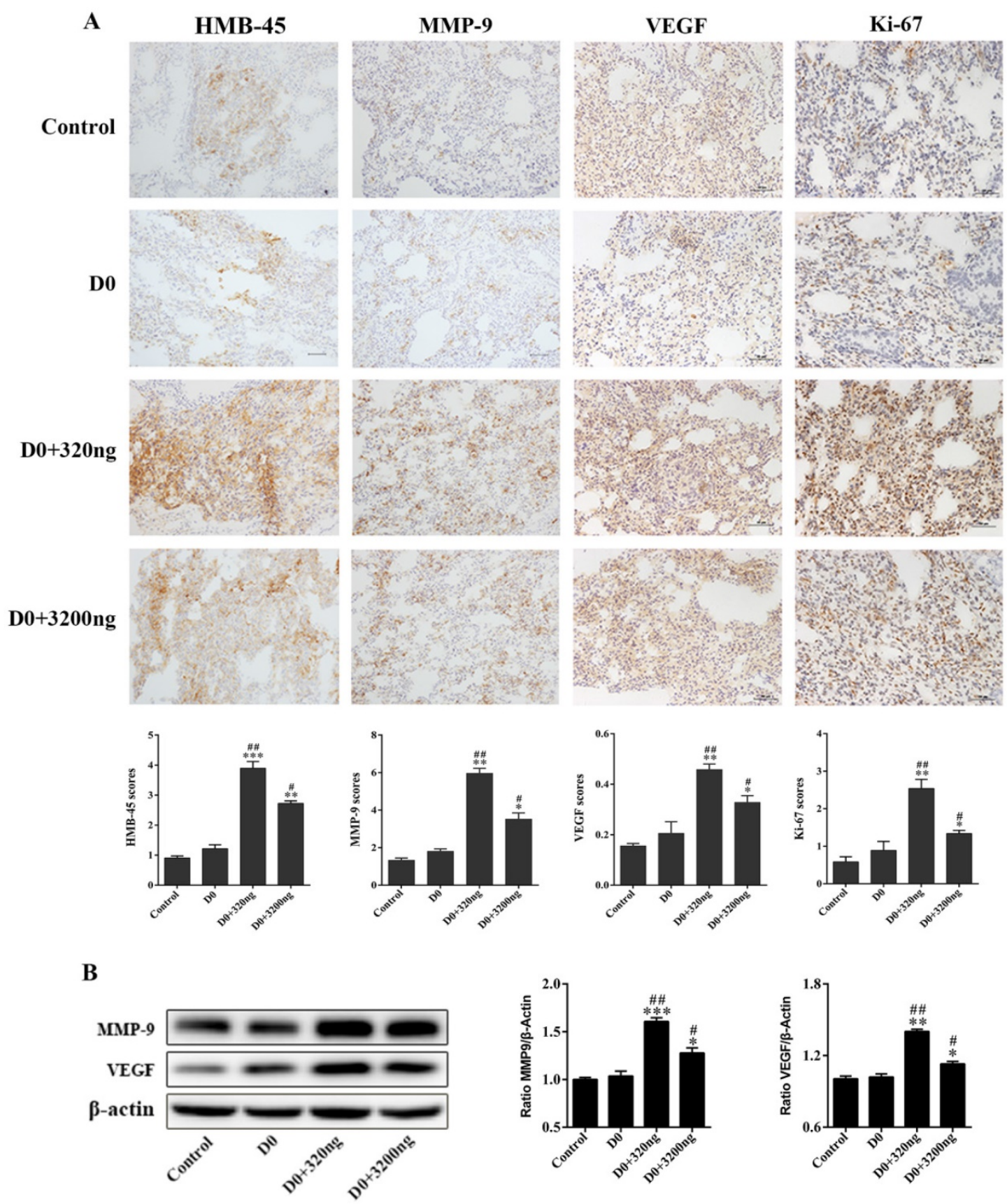

Fig. 6. Extracellular ubiquitin promotes the expression of markers associated with tumor metastasis and proliferation in lung tissues of tumor-bearing mice. (A) B16 melanoma cells $\left(5 \times 10^{5}\right)$ were inoculated into the tail vein of mice. Then, the tail vein was infused with normal saline, D0, D0+320 ng, and D0+3 $200 \mathrm{ng}(200 \mathrm{ul}$ each time for three consecutive times at 24-hour intervals; $n=6$, each group). Mice were sacrificed on the 21 st day after tumor inoculation, and mice lung tissues were harvested. The expression levels of $H M B-45$, MMP-9, VEGF and Ki-67 were detected by immunohistochemistry (original magnification, $\times 200$; scale bar=100 $\mu \mathrm{m}$ ). (B) The expression levels of MMP-9 and VEGF in lung tissues of tumor-bearing mice on the $21^{\text {st }}$ day after tumor inoculation. Data from three independent experiments were expressed as mean \pm standard error of the mean (SEM). Compared with the control group, * represents a $P$-value of $<0.05$, ** represents a $P$-value of $<0.01$, *** represents a $P$-value of $<0.001$; compared with the D 0 group, \# represents a $P$-value of $<0.05$, \# represents a $P$-value of $<0.01$.

Mouse RBCs stored for seven days were found to adversely impact tumor progression and survival rate, which is similar to that for human blood stored for approximately 20 days.[41, 42] Therefore, the blood of mice stored for 15 days (D15) was used to simulate the condition of blood that has been stored for a long duration. Indeed, the transfusion of stored blood increased the rate of tumor growth, invasion and metastasis in the melanoma mice model used in the present study (Figs. 2-7), which confirmed a previous report.[20] Since ubiquitin content in stored blood has been found to increase with storage duration,[32] it was hypothesized that this could play a role in TRIM responses, and result in poor clinical outcome. In the present study, the positive correlation between the concentration of extracellular ubiquitin and in vitro (Fig. 1) and in vivo (Figs. 2-7) tumor progression was demonstrated. The present 
observation of the dose-dependent effect of extracellular ubiquitin is consistent with previous reports on $\mathrm{T}$ and $\mathrm{B}$ cell surface marker expression levels,[43] cAMP levels,[44] the platelet cytotoxicity induced by IgE and INF- $\gamma,[45]$ and the production of TNF- $\alpha$ after the stimulation by LPS.[31, 46]

Among the three concentrations tested, 400 $\mathrm{ng} / \mathrm{ml}$ of extracellular ubiquitin was found to be optimal in promoting proliferation and invasion, and in inhibiting the early and late apoptosis of melanoma cells in mice (Figs. 1B-1D). In vivo studies of H\&E-stained and fluorescence-labeled immunohistochemical sections obtained from melanoma mice inoculated with low (320 ng) and high (3 $200 \mathrm{ng}$ ) amounts of extracellular ubiquitin revealed its positive association with early lung tumor cell migration (Figs. 2C-2E), tumor marker upregulation (Fig. 3), increased tumor size (Fig. 5A), the invasion and metastasis of tumors (Figs. 4B and 5B), weight loss in mice from the $19^{\text {th }}$ day (D19) after inoculation with B16 melanoma cells (Fig. 5C), and lower long-term survival rate (Fig. 5D). Due to rapid tumor growth, there was rapid cachexia onset, especially for mice in the 320 ng ubiquitin group.

The balance of the TH1/TH2 cell ratio is an important indicator of the body's immune stability. The proliferation of $\mathrm{TH} 2$ cytokines increase the invasion and metastasis of cancer cells, while the increase in TH1 cytokines inhibit tumor growth.[47] In the present study, a positive correlation between ubiquitin content in transfusions and the preferential release of $\mathrm{TH} 2$ oncogenic cytokine IL- 6 over TH1
A

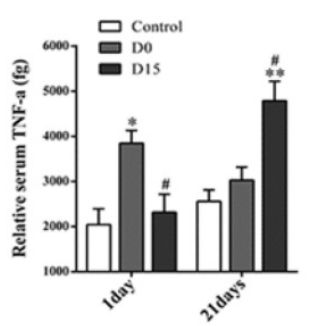

B

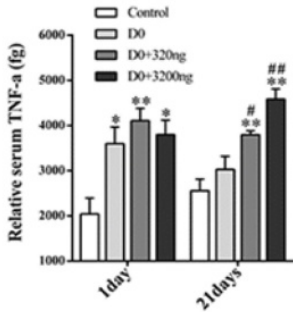

C

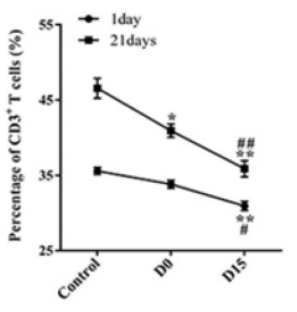

D

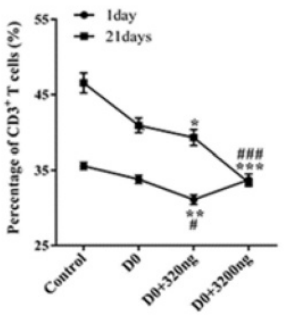

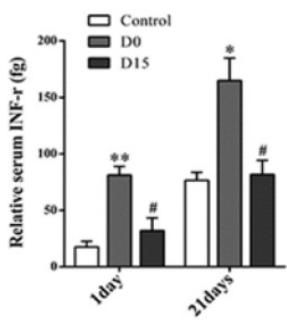
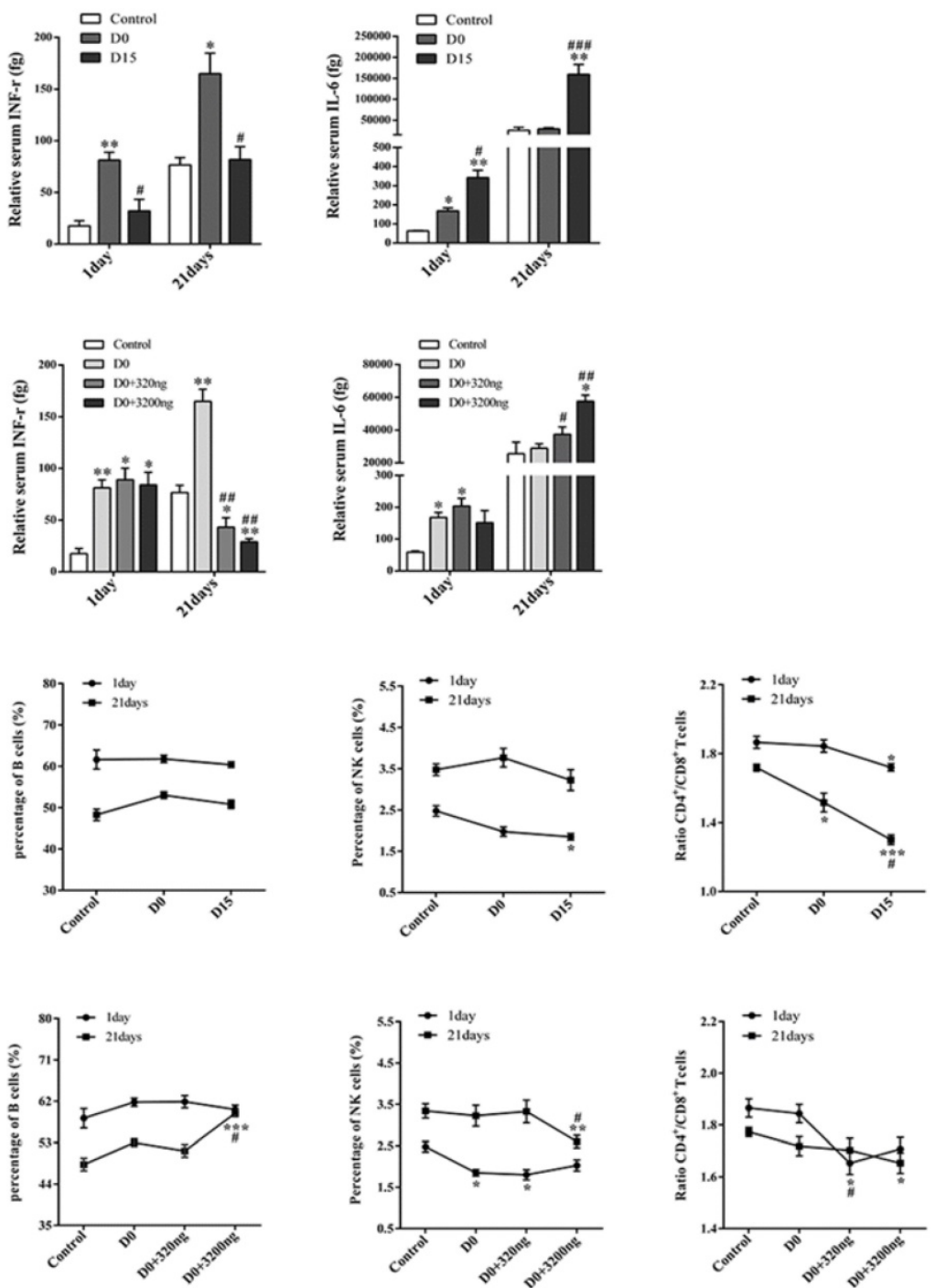

Fig. 7. Extracellular ubiquitin in stored blood affects the expression of TH1/TH2 cytokines and lymphocyte subsets in peripheral blood. (A-B) Tumor-bearing mice were sacrificed on the $1^{\text {st }}$ and $21^{\text {st }}$ day after three consecutive transfusions, and the expression levels of TH1/TH2 cytokines in the peripheral blood of mice in each group were detected ( $n=6$, in each group). (C-D) The expression levels of T cells, B cells and NK cells, and the ratio of CD4+T/CD8 ${ }^{+} T$ cells in peripheral blood of tumor-bearing mice in each group were detected on the $1^{\text {st }}$ day and $21^{\text {st }}$ day after transfusion $(n=6$, each group). Data from three independent experiments were expressed as mean \pm standard error of the mean (SEM). Compared with the control group, * represents a $P$-value of $<0.05$, ** represents is a $P$-value of $<0.01$; compared with the D0 group, $\#$ represents a $P$-value of $<0.05$, \# represents a $P$-value $<0.01$, \#\# represents a $P$-value of $<0.001$. 
anti-tumorigenic cytokines INF- $\gamma$ and TNF- $\alpha$ was demonstrated (Figs. 7A and 7B). The changes in the levels of various cytokines in the tumor microenvironment, including TNF- $\mathrm{a}$ and IL-6, promoted the survival and metastasis of circulating tumor seeds.[48] This also explains the reason for the increased expression of TNF-a in peripheral blood on the $21^{\text {st }}$ day after transfusion.

Lymphocyte subsets are also important indicators that reflect the present immune strength of the body. It is noteworthy that regulatory $\mathrm{T}$ cell plays a significant role in immunosuppression.[49] Ubiquitin has been reported to enhance the immunosuppressive activity of regulatory $\mathrm{T}$ cells.[34] Indeed, it was shown that ubiquitin present in stored blood could inhibit the expression of $\mathrm{CD}^{+} \mathrm{T}$ and NK cells and decrease the $\mathrm{CD} 4{ }^{+} \mathrm{T} / \mathrm{CD} 8^{+} \mathrm{T}$ ratio (Figs. $7 \mathrm{C}$ and 7D), which is consistent with a previous report.[50] This observation could also explain the decrease in the early and late stage apoptosis of melanoma cells (Fig. 1D). Hence, the cellular immune function of tumor patients in the inhibited state is compromised and rendered less effective at identifying and killing mutant cells.[51, 52] In turn, this sets up an environment conducive for tumor growth and metastasis.

Since ubiquitin has been demonstrated to regulate tumor progression in the present study, it was speculated that it could mediate its effect through CXCR4, which is a cell surface chemokine receptor that can recognize and bind to ubiquitin.[35] This chemokine receptor has been shown to enhance the adhesion of melanoma cells to endothelial cells through $\beta 1$ integrin,[53] inhibit the growth and metastasis of melanoma when blocked,[54] and mediate tumor migration[36]. In addition, CXCR4 has been reported to be associated with VEGF, and form a positive feedback loop that promotes angiogenesis and tumor development.[55, 56] The upregulation of VEGF in the lung tissue of tumor-bearing mice (Fig. 3) observed in the present study suggests that ubiquitin could have regulated the expression of VEGF by binding to the CXCR4 receptor, thereby promoting the metastasis and proliferation of melanoma cells. The relationship between ubiquitin, VEGF and CXCR4 could be elucidated in future studies.

In the present study, the function of extracellular ubiquitin was defined and its role in TRIM response and poor clinical prognosis in cancer therapy was clarified. Since extracellular ubiquitin was used for in the present study, a prospective clinical study would be the next logical step to confirm these findings. The results of in vivo imaging have showed that the ubiquitin-treated group produced obvious extra-pulmonary metastatic lesions, and the specific mechanism should be further clarified. Subsequent research should focus on elucidating the source of ubiquitin in stored blood and its molecular mechanism of action, and determine how it is released into stored blood. Since there is no known method to effectively remove or block the effect of ubiquitin present in stored blood, future research in this field should be directed towards devising such strategies to reduce risks associated with transfusion therapy for cancer patients.

In conclusion, it was established that the presence of ubiquitin in transfusions plays a key role in the modulation of the immune response, which in turn increases the probability of melanoma proliferation, invasion and metastasis. Furthermore, the present findings provide insight into the better understanding of TRIM responses in cancer patients, and suggest a novel role for ubiquitin in TRIM, which consequently leads to poor prognosis in cancer therapy. In addition, the present results lay the foundation for the future research and development of blood storage strategies and practices.

\section{Abbreviations}

TRIM: Transfusion-related Immune Modulation; RBCs: Red Blood Cells; CXCR4: C-X-C chemokine receptor type 4; CPDA-1: Citrate Phosphate Dextrose Adenine 1; EGFP: Enhanced Green Fluorescent Protein; DMEM: Dulbecco's Modified Eagle Medium; FBS: Fetal Bovine Serum; PBS: Phosphate-buffered Saline; HMB-45: Melanoma Marker Antibody; MMP-9: Matrix Metalloproteinase 9; VEGF: Vascular Endothelial Growth Factor; IL: Interleukin; TNF: Tumor Necrosis Factor; INF: Interferon; LPS: Lipopolysaccharide.

\section{Acknowledgements}

We thank the Shanghai Research Center for Southern Model Organisms for providing us the cell lines and assisting to establish the metastasis model of melanoma in mice.

\section{Funding}

This work was supported by the National Natural Science Foundation of China (81670173 and 81570166) and the Public Health Leading Academic Discipline Project supported by the Shanghai Municipal Commission of Health and Family Planning (No. 15GWZK0501) and the Sailing Program of Shanghai supported by Shanghai Science and Technology Commission (19YF1405500).

\section{Competing Interests}

The authors have declared that no competing interest exists. 


\section{References}

1. Davis DL, Soldin SJ. Protein ubiquitin is an immunophilin. Therapeutic drug monitoring. 2002; 24: 32-5.

2. Davis DL, Soldin SJ. Identification of ubiquitin as an immunophilin. Biochemical and biophysical research communications. 2000; 277: 325-9.

3. Garcia-Covarrubias L, Manning EW, 3rd, Sorell LT, Pham SM, Majetschak M. Ubiquitin enhances the Th2 cytokine response and attenuates ischemia-reperfusion injury in the lung. Critical care medicine. 2008; 36: 979-82.

4. Szewczuk Z, Stefanowicz P, Wilczynski A, Staszewska A, Siemion IZ, Zimecki $\mathrm{M}$, et al. Immunosuppressory activity of ubiquitin fragments containing retro-RGD sequence. Biopolymers. 2004; 74: 352-62.

5. Majetschak M. Extracellular ubiquitin: immune modulator and endogenous opponent of damage-associated molecular pattern molecules. Journal of leukocyte biology. 2011; 89: 205-19.

6. Majetschak M, Zedler S, Hostmann A, Sorell LT, Patel MB, Novar LT, et al. Systemic ubiquitin release after blunt trauma and burns: association with injury severity, posttraumatic complications, and survival. The Journal of trauma. 2008; 64: 586-96; discussion 96-8.

7. Orlov D, Karkouti K. The pathophysiology and consequences of red blood cell storage. Anaesthesia. 2015; 70 Suppl 1: 29-37, e9-12.

8. Flegel WA, Natanson C, Klein HG. Does prolonged storage of red blood cells cause harm? British journal of haematology. 2014; 165: 3-16.

9. Klein HG, Spahn DR, Carson JL. Red blood cell transfusion in clinical practice. Lancet (London, England). 2007; 370: 415-26.

10. Lelubre C, Vincent JL. Relationship between red cell storage duration and outcomes in adults receiving red cell transfusions: a systematic review. Critical care (London, England). 2013; 17: R66.

11. Koch CG, Li L, Sessler DI, Figueroa P, Hoeltge GA, Mihaljevic T, et al. Duration of red-cell storage and complications after cardiac surgery. The New England journal of medicine. 2008; 358: 1229-39.

12. Zallen G, Offner PJ, Moore EE, Blackwell J, Ciesla DJ, Gabriel J, et al. Age of transfused blood is an independent risk factor for postinjury multiple organ failure. American journal of surgery. 1999; 178: 570-2.

13. van Straten AH, Soliman Hamad MA, van Zundert AA, Martens EJ, ter Woorst JF, de Wolf AM, et al. Effect of duration of red blood cell storage on early and late mortality after coronary artery bypass grafting. The Journal of thoracic and cardiovascular surgery. 2011; 141: 231-7.

14. Leal-Noval SR, Arellano V, Vallejo A, Hernandez A, Ordonez A, Hinojosa R, et al. The influence of the preoperative immune response on blood transfusion requirements in patients undergoing cardiac surgery. Journal of cardiothoracic and vascular anesthesia. 2009; 23: 330-5.

15. Leal-Noval SR, Munoz-Gomez M, Arellano V, Adsuar A, Jimenez-Sanchez M, Corcia Y, et al. Influence of red blood cell transfusion on CD4+ T-helper cells immune response in patients undergoing cardiac surgery. The Journal of surgical research. 2010; 164: 43-9.

16. Blajchman MA. Immunomodulation and blood transfusion. American journal of therapeutics. 2002; 9: 389-95.

17. Remy KE, Hall MW, Cholette J, Juffermans NP, Nicol K, Doctor A, et al. Mechanisms of red blood cell transfusion-related immunomodulation. Transfusion. 2018.

18. Shiba H, Ishida $\mathrm{Y}$, Wakiyama $\mathrm{S}$, Iida $\mathrm{T}$, Matsumoto $\mathrm{M}$, Sakamoto $\mathrm{T}$, et al. Negative impact of blood transfusion on recurrence and prognosis of hepatocellular carcinoma after hepatic resection. Journal of gastrointestinal surgery : official journal of the Society for Surgery of the Alimentary Tract. 2009: 13: $1636-42$

19. Miki C, Hiro J, Ojima E, Inoue Y, Mohri Y, Kusunoki M. Perioperative allogeneic blood transfusion, the related cytokine response and long-term survival after potentially curative resection of colorectal cancer. Clinical oncology (Royal College of Radiologists (Great Britain)). 2006; 18: 60-6.

20. Atzil S, Arad M, Glasner A, Abiri N, Avraham R, Greenfeld K, et al. Blood transfusion promotes cancer progression: a critical role for aged erythrocytes. Anesthesiology. 2008; 109: 989-97.

21. Yao HS, Wang $Q$, Wang WJ, Hu ZQ. Intraoperative allogeneic red blood cell transfusion in ampullary cancer outcome after curative pancreatoduodenectomy: a clinical study and meta-analysis. World journal of surgery. 2008; 32: 2038-46.

22. Cata JP, Wang H, Gottumukkala V, Reuben J, Sessler DI. Inflammatory response, immunosuppression, and cancer recurrence after perioperative blood transfusions. British journal of anaesthesia. 2013; 110: 690-701.

23. Abu-Ghanem Y, Zilberman DE, Dotan Z, Kaver I, Ramon J. Perioperative blood transfusion adversely affects prognosis after nephrectomy for renal cell carcinoma. Urologic oncology. 2017.

24. Kneuertz PJ, Patel SH, Chu CK, Maithel SK, Sarmiento JM, Delman KA, et al. Effects of perioperative red blood cell transfusion on disease recurrence and survival after pancreaticoduodenectomy for ductal adenocarcinoma. Annals of surgical oncology. 2011; 18: 1327-34.

25. Wang CC, Iyer SG, Low JK, Lin CY, Wang SH, Lu SN, et al. Perioperative factors affecting long-term outcomes of 473 consecutive patients undergoing hepatectomy for hepatocellular carcinoma. Annals of surgical oncology. 2009; 16: $1832-42$.

26. Squires MH, 3rd, Kooby DA, Poultsides GA, Weber SM, Bloomston M, Fields $\mathrm{RC}$, et al. Effect of Perioperative Transfusion on Recurrence and Survival after Gastric Cancer Resection: A 7-Institution Analysis of 765 Patients from the US
Gastric Cancer Collaborative. Journal of the American College of Surgeons. 2015; 221: 767-77.

27. van de Watering L. Red cell storage and prognosis. Vox sanguinis. 2011; 100: 36-45.

28. Haas AL. Ubiquitin-mediated processes in erythroid cell maturation. Advances in experimental medicine and biology. 1991; 307: 191-205.

29. Takada K, Nasu H, Hibi N, Tsukada Y, Shibasaki T, Fujise K, et al. Serum concentrations of free ubiquitin and multiubiquitin chains. Clinical chemistry. 1997; 43: 1188-95

30. Haas AL, Wilkinson KD. The large scale purification of ubiquitin from human erythrocytes. Preparative biochemistry. 1985; 15: 49-60.

31. Patel MB, Proctor KG, Majetschak M. Extracellular ubiquitin increases in packed red blood cell units during storage. The Journal of surgical research. 2006; 135: 226-32.

32. Zhu X, Yu B, You P, Wu Y, Fang Y, Yang L, et al. Ubiquitin released in the plasma of whole blood during storage promotes mRNA expression of Th2 cytokines and Th2-inducing transcription factors. Transfusion and apheresis science : official journal of the World Apheresis Association : official journal of the European Society for Haemapheresis. 2012; 47: 305-11.

33. Hod EA, Zhang N, Sokol SA, Wojczyk BS, Francis RO, Ansaldi D, et al. Transfusion of red blood cells after prolonged storage produces harmful effects that are mediated by iron and inflammation. Blood. 2010; 115: 4284-92.

34. Cao Y, Li C, Zhang Q, Wang Y, Xia R. Extracellular ubiquitin enhances the suppressive effects of regulatory $\mathrm{T}$ cells on effector $\mathrm{T}$ cell responses. Clinical laboratory. 2014; 60: 1983-91.

35. Saini V, Marchese A, Majetschak M. CXC chemokine receptor 4 is a cell surface receptor for extracellular ubiquitin. The Journal of biological chemistry. 2010; 285: $15566-76$

36. Yan $\mathrm{L}, \mathrm{Cai} \mathrm{Q}, \mathrm{Xu}$ Y. The ubiquitin-CXCR4 axis plays an important role in acute lung infection-enhanced lung tumor metastasis. Clinical cancer research : an official journal of the American Association for Cancer Research. 2013; 19: 4706-16.

37. Elkin M, Vlodavsky I. Tail vein assay of cancer metastasis. Current protocols in cell biology. 2001; Chapter 19: Unit 192.

38. Steeg PS. Tumor metastasis: mechanistic insights and clinical challenges. Nature medicine. 2006; 12: 895-904.

39. Zhang W, Zhu XD, Sun HC, Xiong YQ, Zhuang PY, Xu HX, et al. Depletion of tumor-associated macrophages enhances the effect of sorafenib in metastatic liver cancer models by antimetastatic and antiangiogenic effects. Clinical cancer research : an official journal of the American Association for Cancer Research. 2010; 16: 3420-30.

40. Gao Q, Qiu SJ, Fan J, Zhou J, Wang XY, Xiao YS, et al. Intratumoral balance of regulatory and cytotoxic $\mathrm{T}$ cells is associated with prognosis of hepatocellular carcinoma after resection. Journal of clinical oncology : official journal of the American Society of Clinical Oncology. 2007; 25: 2586-93.

41. Gilson CR, Kraus TS, Hod EA, Hendrickson JE, Spitalnik SL, Hillyer CD, et al. A novel mouse model of red blood cell storage and posttransfusion in vivo survival. Transfusion. 2009; 49: 1546-53.

42. d'Almeida MS, Jagger J, Duggan M, White M, Ellis C, Chin-Yee IH. A comparison of biochemical and functional alterations of rat and human erythrocytes stored in CPDA-1 for 29 days: implications for animal models of transfusion. Transfusion medicine (Oxford, England). 2000; 10: 291-303.

43. Twomey JJ, Goldstein G, Lewis VM, Bealmear PM, Good RA. Bioassay determinations of thymopoietin and thymic hormone levels in human plasma. Proceedings of the National Academy of Sciences of the United States of America. 1977; 74: 2541-5.

44. Scheid MP, Goldstein G, Boyse EA. The generation and regulation of lymphocyte populations: evidence from differentiative induction systems in vitro. The Journal of experimental medicine. 1978; 147: 1727-43.

45. Pancre V, Pierce RJ, Fournier F, Mehtali M, Delanoye A, Capron A, et al. Effect of ubiquitin on platelet functions: possible identity with platelet activity suppressive lymphokine (PASL). European journal of immunology. 1991; 21: 2735-41

46. Majetschak M, Krehmeier U, Bardenheuer M, Denz C, Quintel M, Voggenreiter G, et al. Extracellular ubiquitin inhibits the TNF-alpha response to endotoxin in peripheral blood mononuclear cells and regulates endotoxin hyporesponsiveness in critical illness. Blood. 2003; 101: 1882-90.

47. Yu H, Kortylewski M, Pardoll D. Crosstalk between cancer and immune cells: role of STAT3 in the tumour microenvironment. Nature reviews Immunology. 2007; 7: 41-51.

48. Nguyen DX, Bos PD, Massague J. Metastasis: from dissemination to organ-specific colonization. Nature reviews Cancer. 2009; 9: 274-84.

49. Zou W. Regulatory T cells, tumour immunity and immunotherapy. Nature reviews Immunology. 2006; 6: 295-307.

50. Kristian T, Ilkka L, Juuso J, Aila KK, Minna O, Riku T, et al. T-cell subsets in peripheral blood and tumors of patients treated with oncolytic adenoviruses. Molecular therapy : the journal of the American Society of Gene Therapy. 2015; 23: 964-73

51. Zhu Z, Cuss SM, Singh V, Gurusamy D, Shoe JL, Leighty R, et al. CD4+ T Cell Help Selectively Enhances High-Avidity Tumor Antigen-Specific CD8+ T Cells. Journal of immunology (Baltimore, Md : 1950). 2015; 195: 3482-9.

52. Bos R, Sherman LA. CD4+ T-cell help in the tumor milieu is required for recruitment and cytolytic function of CD8+ T lymphocytes. Cancer research. 2010; 70: 8368-77. 
53. Cardones AR, Murakami T, Hwang ST. CXCR4 enhances adhesion of B16 tumor cells to endothelial cells in vitro and in vivo via beta(1) integrin. Cancer research. 2003; 63: 6751-7.

54. Kim M, Koh YJ, Kim KE, Koh BI, Nam DH, Alitalo K, et al. CXCR4 signaling regulates metastasis of chemoresistant melanoma cells by a lymphatic metastatic niche. Cancer research. 2010; 70: 10411-21.

55. Zhang P, Dong L, Yan K, Long H, Yang TT, Dong MQ et al. CXCR4-mediated osteosarcoma growth and pulmonary metastasis is promoted by mesenchymal stem cells through VEGF. Oncology reports. 2013; 30: 1753-61.

56. Sun X, Charbonneau C, Wei L, Yang W, Chen Q, Terek RM. CXCR4-targeted therapy inhibits VEGF expression and chondrosarcoma angiogenesis and metastasis. Molecular cancer therapeutics. 2013; 12: 1163-70. 